\title{
15. COMMISSION POUR L'ETUDE PHYSIQUE DES COMETES
}

\author{
Report of Meetings
}

President: F. L. Whipple.

SeCRETARY: V. Vanýsek.

Commission 15 met in two announced sessions on 24 and 29 August, and in one additional session in the afternoon on 29 August.

PART 1

\section{Administrative Business, Meeting 24 August 1967}

The President introduced the general plans of the agenda as well as the methodology of correcting Draft Reports. The members were asked to inform the Secretary only about errors, misinterpretations and missing papers in the bibliography, which would then be corrected. The duly corrected Draft Report was finally approved by the President and by the Secretary. Some proposed changes of whole paragraphs were refused to reduce printing costs.

\section{Administrative Business, Meeting 29 August 1967}

The second session was devoted to the discussions about the progress of the proposition which was recommended during the previous Hamburg General Assembly (see Trans. IAU, XIIB, 186ff., $1964)$ and to the new propositions and suggestions made by the members.

\section{Progress of 'The Atlas of Characteristic Comet Photographs' \\ (Committee: Donn, Dossin, Haser, Vanýsek and Wurm)}

Dr Wurm briefly summarized the work done by him, Dr Donn and Dr Rahe in the last year on the Atlas of Cometary Forms on film prints. The technique proposed by Dr Wurm at the last IAU meeting is used, and Dr Rahe continues preparing the final redaction of the Atlas. It was concluded that a Commission recommendation might be of help in the support of this useful work.

Because the new plan of Dr Richter to publish the Isophotometric Atlas of Cometary Forms seems to be valuable, too, the joint final text of the Recommendation included Richter's as well as Wurm's plans on Atlases (see Recommendations). Dr Richter intends to publish an isophotometric morphological atlas of comets on the base of about 100-150 isophotometric pictures which describe the photometric structure and development of these comets by means of equidensities.

\section{New Proposals and Suggestions Made by Members}

The President received before the Prague General Assembly the following propositions, which are presented in summarized form to the Commission:

(1) A Coordinated International Observational Programme for Comets (Donn and Wurm);

(2) Telegraphic Notices on Special Comet Characteristics (Miller);

(3) Cometary Position Plates with Filters for $\mathrm{CN}, \mathrm{C}_{2}$ or Continuum (Vanýsek);

(4) Establishing of a Small Standing Committee for Coordination (Donn);

(5) Cometography; a compilation kept current, of positional and physical observations of comets (Marsden);

During the Assembly an additional suggestion was presented by Dr. Vsekhsvyatsky:

(6) A Comet Searching Service on Sky Photographs. 
The President outlined the goals of proposals and stated that the propositions made by Wurm and Donn practically included suggestions made by Miller and Vanýsek and might be discussed simultaneously.

In the discussion among Drs Dossin, Levin, Swings, Vanýsek, Whipple and Wurm the principles of Recommendation II were agreed upon.

Dr Swings pointed out that the above-mentioned suggestions of detailed observational goals had been presented by other astronomers in other formulations previously. The fact that similar ideas reappear confirms their necessity but also the difficulties in the realization of proposed plans.

For the international cooperation in the physical observation of comets, the following working group was established: Biermann (chairman), Bappu, Dossin, Hirose, Konopleva, Miller, Mrkos, Roemer.

Dr Marsden's plan was found to be a very useful one, but the number of the data to be published seemed extremely high.

Everyone agreed with Dr Vsekhsvyatsky that cometary studies are becoming increasingly important and that it would be desirable to search all sky photographs immediately after exposure for possible new comets. But Dr Roemer and others pointed out that such an effort would be very timeconsuming and too expensive for practical implementation.

The Commission tabled the recommendation.

\section{Actions of Commission 15}

Recommendation 1: Noting the extreme value of central repositories for and dissemination of cometary photographs and spectrograms, Commission 15 recommends the publication of an isophotometric atlas of comets on the basis of equidensities by the method of Richter and Hoegner, the publication of an Atlas of Characteristic Comet Photographs prepared by Donn, Rahe and Wurm, and the cooperation of all observatories in making their cometary material available for these purposes.

Recommendation 2: In view of the expanding potentials for cometary observations by new groundbased and space techniques, Commission 15 appoints a Coordination Committee for Observation of Comets and recommends the full cooperation of all observatories and the Central Bureau for Astronomical Telegrams, Cambridge, Mass., in planning observing programs, in reporting unusual cometary activity and in making special observations of comets.

The following communications were presented at the Scientific Meetings:

W. Schlosse: Statistical Properties of Rays in Comet Morehouse 1908 III.

K. Pflug: Spectrophotometric Measurements in the Head of Comet Arend-Roland (1957 III).

R.F.Probstein: A Theory of Dust Comets (joint paper with M.L. Finson).

J.C. Brandt: The Distribution of Aberration Angles of Type-I Comet Tails.

E. Roemer: Frequency Functions of Nuclear Dimensions in Comets.

R. Lüst: Artificial Ion Cloud Experiments.

L. Biermann: The Emission Lines of Atomic Hydrogen in Comets.

C. Arpigny: On the Interpretation of Some Features Observed in Cometary Spectra.

A. H. Delsemme: Progress Report on the Theory of Evaporation of the Cometary Nucleus.

o.V. Dobrovolsky: Statistical Dependence Between the Brightness and Coma Diameter.

L.M. Sulman: Gas Dynamics of the Nuclear Regions of Comets.

$V$. Vanýsek: Lifetimes of $\mathrm{CN}$ and $\mathrm{C}_{2}$ Molecules.

D. O. Mohnač: Photodissociation and Lifetimes of the $\mathrm{C}_{2}$ Molecules in the Cometary Atmospheres and Related Problems.

S. K. Vsekhsvyatsky: New Facts About the Origin of Comets.

J. Witkowski: Statistical Investigations on the Distribution of Perihelia of Cometary Orbits.

Z. Sekanina: Non-gravitational Effects in Comets and Cometary Splits. 